\title{
Public Eye toward COVID-19: A Systematic Review
}

\author{
Behzad Fouladi Dehaghi ${ }^{1,2}$, Gholamheidar Teimori-Boghsani ${ }^{3,4}$, Leila Ibrahimi Ghavamabadi ${ }^{5 *}$, Abbas Mohammadi $^{1,2}$ \\ ${ }^{1}$ Environmental Technologies Research Center, Ahvaz Jundishapur University of Medical Sciences, Ahvaz, Iran; ${ }^{2}$ Department of \\ Occupational Health, School of Public Health, Ahvaz Jundishapur University of Medical Sciences, Ahvaz, Iran; ${ }^{3}$ Department of \\ Occupational Health Engineering, School of Health, Torbat Heydariyeh University of Medical Sciences, Torbat Heydariyeh, Iran; \\ ${ }^{4}$ Health Sciences Research Center, Torbat Heydariyeh University of Medical Sciences, Torbat Heydariyeh, Iran; ${ }^{5}$ Department of \\ Environmental management-HSE, Ahvaz Branch, Islamic Azad University, Ahvaz, Iran
}

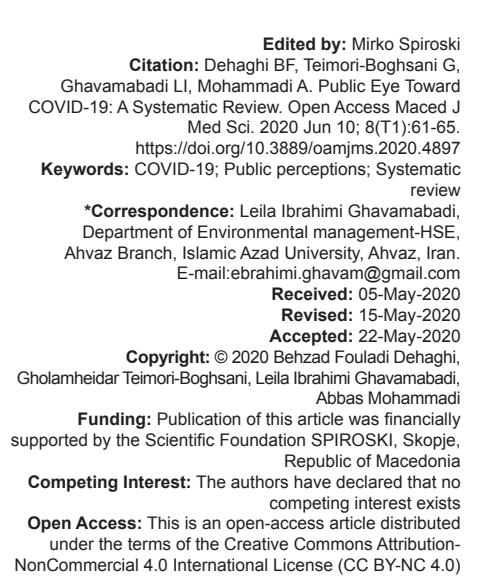

Abstract

BACKGROUND: The general public has an important role in controlling the spread of infectious diseases by pursuing prophylactic measures.

AIM: The aim of the present systematic review was to describe public perceptions, knowledge, attitudes, and behaviors toward COVID-19.

METHODS: In this review, articles were extracted from the Google Scholar, Embase, Scopus, Web of Science and PubMed search engines. The main keywords for the search were coronavirus, COVID-19, public perceptions knowledge, attitudes, and behaviors.

RESULTS: The knowledge level toward novel coronavirus in different countries was generally high, and it had an increasing pattern during the pandemic phase. Furthermore, the insight self-efficacy, perceived severity of the COVID-19, and intention to meet the needs of preventive measures have increased notably. Furthermore, there are several misconceptions and unconfirmed beliefs in the general public in the case of preventive measures recommended, in particular.

CONCLUSIONS: Health authorities and other disease control centers should monitor public misconceptions and perceptions continuously and manage a trusting platform to be presented to the public, especially in the case of a novel disease outbreak.

\section{Introduction}

In late 2019, a new strain of coronavirus (COVID-19) spread rapidly around the world and it led to the second global pandemic in the $21^{\text {st }}$ century. The "early phase" began in December 2019 with the outbreak of the disease in Wuhan, China. Later, other cases of the disease were reported in other countries such as Korea, Japan, Italy, Japan, Iran, and the United States [1]. On January 30, 2020, the World Health Organization (WHO) declared it as a "Health Emergency of International Concern" and on 11 March, WHO defined COVID-19 as a pandemic [2].

As of April 20, 2020, a total of 2,428,274 cases, 166,126 deaths, and 636,723 recovered in the worldwide have been reported [3]. The clinical and epidemiological characteristics revealed that $18.5 \%$ of the patients with SARA developed to the severe phase, which is defined by acute respiratory distress syndrome, dyspnea, and coagulation dysfunction [4], [5]. Initially, with the aim of limiting the prevalence of coronavirus, measures were taken according to the strategy of most countries to contain/delay it. This strategy included preventing close contact, isolating cases, and quarantining. Most countries also focused on a reduction strategy aimed at minimizing the effects of the disease. Due to the fact that antiviral drugs have no effect and yet there is no vaccine for this disease; therefore, the emphasis is on strict personal hygiene, frequent handwashing, covering the mouth when coughing, social distancing (maintaining a distance of at least one meter), and avoiding crowded places. The general public has a key role in controlling the disease during and after the pandemic by adopting governmentrecommended prophylactic measures. The protection motivation theory, as a theoretical model, has declared that behavioral manner may be influenced by public perceptions of personal susceptibility to the disease, disease severity, effectiveness of recommended measures, and self-efficacy (confidence in the ability to perform the recommended measures) [6]. Furthermore, knowledge, attitudes, and practices (KAP) of peoples have an important role in successful control and fighting against COVID-19 [7], [8]. Social behavior may also be impressed by the knowledge and more affective factors, like the feeling of anxiety is of importance [9], [10]. Intuition into behaviors and public perceptions during 
a pandemic can provide useful information for risk relevance. The COVID-19 pandemic was specified by changes in risk, propaganda, and recommended measures during the different phases. This situation is an opportunity to gain insight into behaviors and public perceptions in the world. The aim of the present systematic review was to describe public perceptions, knowledge, attitudes, and behaviors toward COVID-19.

\section{Methods}

\section{Search strategy and criteria}

A narrative-systematic search in the scientific literature to find studies on KAP, public perceptions, and behaviors during the COVID-19 pandemic was performed on April 29 in 2020. PubMed, SCOPUS, Web of Science, Embase, and Google Scholar databases were searched with predefined online search terms. The terms which were used represented public perceptions of risk (perceived vulnerability and disease severity), $\mathrm{KAP}$, willingness to take preventive measures, and actual behavior.

Inclusion criteria contained these items: Original research studies which were centered on public perceptions, behaviors, knowledge, and attitudes during the COVID-19 pandemic. Furthermore, only articles published in the English language were selected.

The excluded studies were as follows: The studies regarding pregnant women, diabetics' patients and dialyzed patients, editorials, meta-analysis, and systematic reviews. However, the reference lists were searched for relevant papers. Further, a manual search was conducted with the first authors' reference database. This study focused on the description of studies, results, their application, and limitations in qualitative composition, not on the meta-analysis.

The PRISMA guidelines for the literature search and preparation of the article were used [11].

The first author (BF) could gather 234 articles. In the primary evaluation on the basis of title and abstract, 187 records were excluded from the study. Then, the full-text articles $(n=47)$ were screened independently by the first author (BF) and the third author (LI). Any case of disagreement was discussed fully and further study and evaluation with the help of other authors were used to resolve data mining differences.

\section{Results}

Figure 1 presents the study flow diagram. Table 1 represents the characteristics of the studies included in this narrative review. The studies were conducted in China $(n=2)$, Iran $(n=2)$, the United States, and United Kingdom ( $n=1)$, and the data had gathered during the coronavirus pandemic phase.
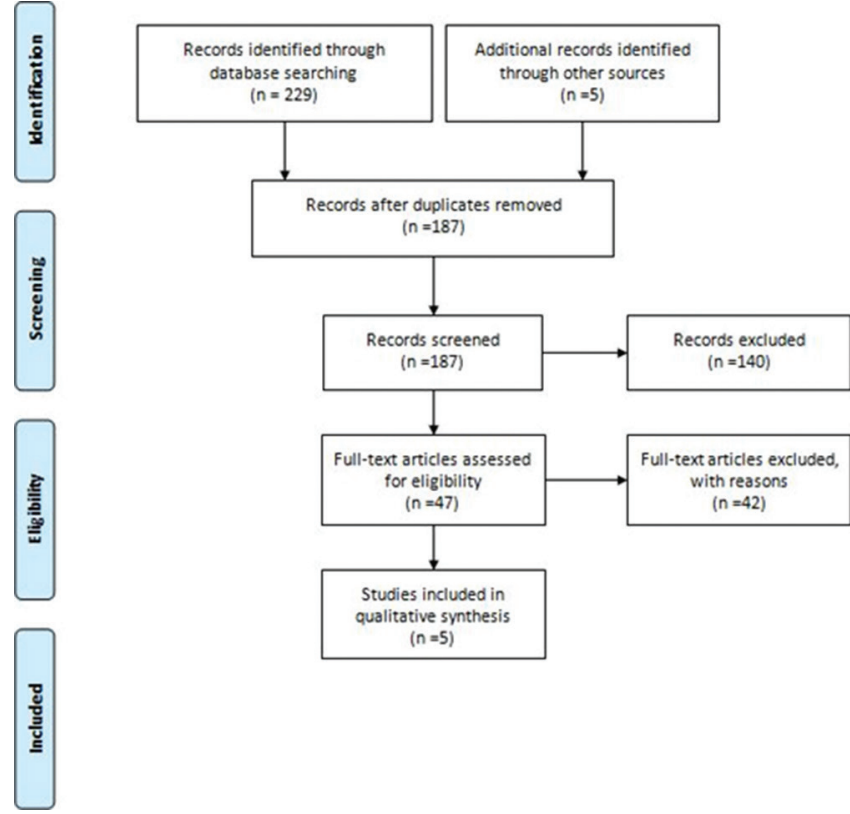

Figure 1: Systematic review process

Zhong et al. surveyed KAP toward COVID-19 in China. The data were collected with the aim of an online KAP questionnaire (containing 12 questions for knowledge, 2 questions for attitudes, and 2 questions for practices). A total of 6910 participants were included in the study. The results revealed that public knowledge has a high level about the novel coronavirus. Moreover, this subject was highlighted in women groups and high level educated participants. Furthermore, holding an optimistic attitude, more than $90 \%$ of participants believed that the coronavirus will finally be successfully controlled. In short, they suggested that health education programs can be helpful in improving COVID-19 knowledge, encouraging an optimistic attitude, and maintaining safe personal hygiene practices [12]. Furthermore, Taghrir et al. studied knowledge, preventive behaviors, and risk perception of SARS-CoV-2 in medical students in Iran. The data were gathered by an online questionnaire that had 26 items (15 questions about knowledge, 9 questions regarding preventive measures, and 2questionsaboutCOVID-19 riskperception). Two hundred forty questionnaires were fully completed by

Table 1: The characteristics of the studies included in this review

\begin{tabular}{|c|c|c|c|c|c|c|c|c|}
\hline Study & $\mathrm{n}$ (missed) & Country & Survey method & Study design* & Content of questionnaire & Gender & Age ranges & Occupation \\
\hline Zhong et al. [12] & $6919(9)$ & China & Online & CS & KAP & $\mathrm{F}, \mathrm{M}$ & $16-50^{+}$ & $\mathrm{PL}, \mathrm{S}, \mathrm{U}, \mathrm{ML}$ \\
\hline Taghrir et al. [13] & $240(0)$ & Iran & Online & CS & $\mathrm{K}$ and $\mathrm{PB}$ and $\mathrm{RP}$ & $\mathrm{F}, \mathrm{M}$ & $20-30$ & MS \\
\hline Nemati et al. [14] & $85(0)$ & Iran & Online & CS & $\mathrm{A}$ and $\mathrm{K}$ & $F, M$ & $23-40^{+}$ & $\mathrm{HCW}$ \\
\hline Geldsetzer [15] & $6000(24)$ & US and UK & Online & CS & $\mathrm{K}$ and $\mathrm{PB}$ and $\mathrm{RP}$ & $\mathrm{F}, \mathrm{M}$ & $18-58^{+}$ & $\mathrm{HCW}, \mathrm{O}$ \\
\hline Zhou et al. [16] & $1375(0)$ & China & Online & CS & KAP & $\mathrm{F}, \mathrm{M}$ & none & HCW \\
\hline
\end{tabular}

${ }^{*} \mathrm{CS}$ indicates cross-sectional, D: Demographic, KAP: Knowledge, attitudes and practices, PB: Preventive behaviors, RP: Risk perception, A: Anxiety, F: Female, M: Male, HCW: Health care worker, MS: Medical student

S: Student, PL: Physical labor, U: Unemployed, ML: Mental labor, O: Other. 
students. The knowledge and related knowledge about COVID-19 showed high levels. Furthermore, the mean rate of practicing preventive behaviors and performance in preventive behaviors was high. However, the participants' risk perception was in the moderate range and it had a negative relation with preventive behaviors. Risk perception was different between groups with varying educational levels and also in gender sub-groups. The female groups had a lower range of risk perception [13]. In another study, Nemati et al. assessed knowledge and anxiety toward COVID-19 among nurses in Iran. A total of 85 nurses were enrolled in the study and answered the questions through a self-administered questionnaire. The results illustrated that the anxiety level toward novel coronavirus among nurses was reported to be high. Furthermore, their awareness in relation to infectious disease was well. Moreover, more than $50 \%$ of the participants had good knowledge about the disease. Most of them rated their information as a high level. However, despite this stated high level of knowledge, more information is still needed to be provided by the World Health Organization and the National Iranian Ministry of Health [14]. Furthermore, Geldsetzer reported the results of a rapid online survey on public perception toward COVID-19 in the United States and the United Kingdom. The total number of participants who completed the questionnaires was 5974 (2986 from the US and 2988 from the UK). The knowledge level in participants in both countries was well. Furthermore, the results showed that most of the participants believed that common surgical masks are highly effective in preventing infection with COVID-19. Regardless of the reported high level of information, about $25 \%$ of participants stated a need to seek more information on SARS-CoV-2 from health-care staff. However, a large proportion of participants had misconceptions about how to prevent an infection disease and how to seek medical care [15]. In addition, Zhou et al. studied the KAP of healthcare workers regarding COVID-19 in China. The data were collected by a questionnaire. One thousand three hundred fifty-seven of healthcare workers from 10 hospitals collaborated in the study. The results showed that $89 \%$ of healthcare workers had satisfactory knowledge of COVID-19, more than $85 \%$ feared self-infection with the novel coronavirus, and $89.7 \%$ followed correct practices toward SARS-Cov-2. Furthermore, the knowledge level and some other risk factors, including job category and work experience, affected health workers' attitudes, and practice concerning new coronavirus. Steps need to be taken to protect healthcare workers from risks related to working hours, work experience, job category, educational achievement, and front line healthcare workers [16].

\section{Discussion}

In this population-based narrative- systematic review, the results revealed that the knowledge level toward novel coronavirus in different countries was generally high, and it had an increasing pattern during the pandemic phase. The public information in case of preventing virus transmission was estimated to be well [12], [13], [14], [15], [16]. Similar results have been found in case of other epidemic or pandemic diseases such as flu, SARS, and MERS [17], [18], [19]. The discerned self-efficacy, perceived severity of the COVID-19, and intention to meet the needs of preventive measures have increased notably [12], [13], [14], [15], [16]. Furthermore, during the pandemic, the amount of trust in different forms of media experienced a dramatic change; the trust in social network media decreased due to fake news and exaggerations in mortality of COVID-19 [20]. Therefore, the discerned reliability of information from the governmental authorities such as ministry of health increased. On the other hand, in healthcare workers feeling of anxiety increased, especially for their family to be infected by COVID-19 [14], [21]. During the pandemic phase, the discerned vulnerability had increased and undertakers did most of the cautionary measures [15], [16]. This was in line with the fact that the number of infected people and the number of fatalities increased rapidly. A similar finding is reported in other epidemics (flu, SARS) [22], [23]. On the contrary, there are several misconceptions and unconfirmed beliefs in the general public in the case of preventive measures recommended, in particular. In this regard, such misconceptions are reported during $\mathrm{H} 1 \mathrm{~N} 1$ flu epidemic [24], [25]. In addition, most respondents believed that it was less likely for themselves to become infected to COVID-19 than other people at the peak of the pandemic. A similar misconception was observed in other studies on the flu epidemic [22], [23]. Since, during the pandemic, the public in different countries felt unrealistically optimistic regarding the risk of being infected by the virus. This optimism bias could stem from the belief that the illness is not as severe and fatal as it is spoken of in the media and people are able to protect themselves by taking hygienic preventive measures. Considering this fact that the present review has focused on the published papers on COVID-19 pandemic which is a hot topic in past 4 months, the number of studies which were found is not large; so, the small number of articles being reviewed here is the result of the coronavirus tide is not over yet. Despite this limitation, the findings of this review present useful information for further research on knowledge, attitudes, practices, perception, behavior, and anxiety of general public in case of COVID-19 infectious diseases, which can pave the way to achieve successful changes in public behavior that reduce the spread and fatality of the disease. Furthermore, better ways of risk communication could be applied to remove misconceptions and misperceptions in the general public. It is recommended that a risk communication policy should be established to conduct research on behavioral responses and risk perception of the general public during and after the pandemic. Furthermore, it is 
recommended to use health behavior theories in further studies so that new insight into basic perceptions and behaviors could be achieved.

\section{Conclusion}

Regarding the unstable nature of public understanding and behaviors' health authorities and other disease control centers should monitor public misconceptions and perceptions continuously and manage a trusting platform to be presented to the public, especially in the case a novel disease outbreak.

\section{References}

1. Kenneth McIntosh M. Coronavirus Disease 2019 (COVID-19); 2020. Available from: https://www.uptodate.com/ contents/126981. [Last accessed on 2020 May 02].

2. Available from: http://www.euro.who.int/en/health-opics/ emergencies/pages/news/news/2020/01/2019-ncov-outbreakis-an-emergency-of-international-concernWHO-noiaeoic. [Last accessed on 2020 May 02].

3. World Health Organization. NC-nsr-WHO. Geneva: World Health Organization; 2019.

4. Lai CC, Shih TP, Ko WC, Tang HJ ,Hsueh PR. Severe acute respiratory syndrome coronavirus 2 (SARS-CoV-2) and coronavirus disease-2019 (COVID-19): The epidemic and the challenges. Int J Antimicrob Agents. 2020;55(3):105924. https:// doi.org/10.1016/j.ijantimicag.2020.105924

PMid:32081636

5. Chen N, Zhou M, Dong X, Qu J, Gong F, Han Y, et al. Epidemiological and clinical characteristics of 99 cases of 2019 novel coronavirus pneumonia in Wuhan, China: A descriptive study. Lancet. 2020;395(10223):507-13. https://doi.org/10.1016/ s0140-6736(20)30211-7

PMid:32007143

6. Norman PB, Seydel ER. Protection motivation theory. In: Conner M, Norman P, editors. Predicting Health Behaviour: Research and Practice with Social Cognition Models. Maidenhead: Open University Press; 2005. p. 81-126.

7. Tachfouti N, Slama K, Berraho M, Nejjari C. The impact of knowledge and attitudes on adherence to tuberculosis treatment: A case-control study in a Moroccan region. Pan Afr Med J. 2012;12:52.

PMid:22937192

8. Ajilore K, Atakiti I, Onyenankeya K. College students' knowledge, attitudes and adherence to public service announcements on Ebola in Nigeria: Suggestions for improving future Ebola prevention education programmes. Health Educ J. 2017;76:64860. https://doi.org/10.1177/0017896917710969

9. Chapman GB, Coups EJ. Emotions and preventive health behavior:Worry, regret, and influenzavaccination. Health Psychol. 2006;25(1):82-90 https://doi.org/10.1037/0278-6133.25.1.82. PMid: 16448301

10. Weinstein ND, Kwitel A, McCaul KD, Magnan RE, Gerrard M,
Gibbons FX. Risk perceptions: Assessment and relationship to influenza vaccination. Health Psychol. 2007;26(2):146-51. https://doi.org/10.1037/0278-6133.26.2.146

PMid: 17385965

11. Moher D, Shamseer L, Clarke M, Ghersi D, Liberati A Petticrew M, et al. Preferred reporting items for systematic review and meta-analysis protocols (PRISMA-P) 2015 statement. Syst Rev. 2015;4(1):1. https://doi.org/10.1186/2046-4053-4-1 PMid:25554246

12. Zhong BL, Luo W, Li HM, Zhang QQ, Liu XG, Li WT, et al Knowledge, attitudes, and practices towards COVID-19 among Chinese residents during the rapid rise period of the COVID-19 outbreak: A quick online cross-sectional survey. Int J Biol Sci. 2020;16(10):1745-52. https://doi.org/10.7150/ijbs.45221 PMid:32226294

13. Taghrir MH, Borazjani R, Shiraly R. COVID-19 and Iranian medical students; a survey on their related-knowledge, preventive behaviors and risk perception. Arch Iran Med. 2020;23(4):249-54. https://doi.org/10.34172/aim.2020.06 PMid:32271598

14. Nemati M, Ebrahimi B, Nemati F. Assessment of Iranian nurses knowledge and anxiety toward COVID-19 during the current outbreak in Iran. Arch Clin Infect Dis. 2020;15:e102848 .https:// doi.org/10.5812/archcid.102848

15. Geldsetzer P. Knowledge and perceptions of COVID-19 among the general public in the United States and the United Kingdom: A cross-sectional online survey. Ann Intern Med. 2020:M200912. https://doi.org/10.7326/m20-0912

PMid:32196071

16. Zhou M, Tang F, Wang Y, Nie H, Zhang L, You G, et al. Knowledge, attitude and practice regarding COVID-19 among healthcare workers in Henan, China. J Hosp Infect. 2020;105(2):183-7. https://doi.org/10.1016/j.jhin.2020.04.012 PMid:32278701

17. Aburto NJ, Pevzner E, Lopez-Ridaura R, Rojas R, LopezGatell H, Lazcano E, et al. Knowledge and adoption of community mitigation efforts in Mexico during the $2009 \mathrm{H} 1 \mathrm{~N} 1$ pandemic. Am J Prev Med. 2010;39(5):395-402. https://doi. org/10.1016/j.amepre.2010.07.011 PMid:20965376

18. Lin Y, Huang L, Nie S, Liu Z, Yu H, Yan W, et al. Knowledge, attitudes and practices (KAP) related to the pandemic (H1N1) 2009 among Chinese general population: A telephone survey. BMC Infect Dis. 2011;11:128. https://doi. org/10.1186/1471-2334-11-128

19. Marshall H, Tooher R, Collins J, Mensah F, Braunack-Mayer A, Street $\mathrm{J}$, et al. Awareness, anxiety, compliance: Community perceptions and response to the threat and reality of an influenza pandemic. Am J Infect Control. 2012;40(3):270-2. https://doi.org/10.1016/j.ajic.2011.03.015 PMid:21782279

20. Zarocostas J. How to fight an infodemic. Lancet 2020;395(10225):676. https://doi.org/10.1016/ s0140-6736(20)30461-x PMid:32113495

21. Huang $Y$, Zhao N. Generalized anxiety disorder, depressive symptoms and sleep quality during COVID-19 epidemic in China: A web-based cross-sectional survey. medRxiv. 2020;2020:112954. https://doi.org/10.21203/rs.3.rs-17172/v1 PMid:32325383

22. Bults M, Beaujean DJ, de Zwart O, Kok G, van Empelen P, van Steenbergen JE, et al. Perceived risk, anxiety, and behavioural responses of the general public during the early phase of the Influenza A (H1N1) pandemic in the Netherlands: Results of three consecutive online surveys. BMC Public Health. 
2011;11(1):2. https://doi.org/10.1186/1471-2458-11-2

PMid:21199571

23. Cowling BJ, Ng DM, Ip DK, Liao Q, Lam WW, Wu JT, et al. Community psychological and behavioral responses through the first wave of the 2009 influenza $A(H 1 N 1)$ pandemic in Hong Kong. J Infect Dis. 2010;202(6):867-76. https://doi. org/10.1086/655811

PMid:20677945

24. Leung GM, Lam TH, Ho LM, Ho SY, Chan BH, Wong IO, et al. The impact of community psychological responses on outbreak control for severe acute respiratory syndrome in Hong Kong J Epidemiol Community Health. 2003;57(11):857. https://doi. org/10.1136/jech.57.11.857

PMid: 14600110

25. Lau JT, Tsui H, Kim JH, Griffiths S. Perceptions about status and modes of H5N1 transmission and associations with immediate behavioral responses in the Hong Kong general population. Prevent Med. 2006;43(5):406-10. https://doi.org/10.1016/j. ypmed.2006.06.007

PMid:16860379

Author Queries???

AQ7: Kindly provide significant 